\title{
ORIGINAL WORK
}

\section{Effect of Early Tracheostomy on Mortality of Mechanically Ventilated Patients with Guillain-Barré Syndrome: A Nationwide Observational Study}

\author{
Naoki Yonezawa ${ }^{1 *}$, Taisuke Jo ${ }^{2}$, Hiroki Matsui ${ }^{1}$, Kiyohide Fushimi ${ }^{3}$ and Hideo Yasunaga ${ }^{1}$ \\ (c) 2020 Springer Science+Business Media, LLC, part of Springer Nature and Neurocritical Care Society
}

\begin{abstract}
Background: Patients with Guillain-Barré syndrome (GBS) who require mechanical ventilation (MV) are regarded as candidates for early tracheostomy because of the high risk of prolonged MV; however, the association between early tracheostomy and favorable outcomes in patients with GBS remains unclear. In this study, we evaluated the association between early tracheostomy and outcomes in mechanically ventilated patients with GBS.

Methods: This retrospective observational study included adult patients with GBS identified in the Japanese Diagnosis Procedure Combination national inpatient database from July 1, 2010, to March 31, 2018, who initiated MV within the first week of admission and who received MV for more than 1 week. Early tracheostomy was defined as tracheostomy performed within 7 days of MV. The primary outcome was in-hospital mortality, and the secondary outcomes were 28-day mortality, nosocomial pneumonia, length of hospital stay, length of intensive care unit (ICU) stay, duration of MV, duration of sedation, duration of analgesia, duration of delirium, and total hospitalization costs. Propensity scores for early tracheostomy were calculated using a logistic regression model on the following variables: age; sex; body mass index; Japan Coma Scale status at admission; Charlson comorbidity index score; comorbidity of chronic pulmonary disease; complication of pneumonia at admission; complication of hyponatremia at admission; neurological presentation at admission; ambulance use; referral from other hospitals; treatment year; days from hospital admission to MV initiation; ICU admission until the day of MV initiation; and treatments until the day of MV initiation. Stabilized inverse probability of treatment weighting analyses was performed to compare the outcomes between patients with and without early tracheostomy.
\end{abstract}

Results: Among 919 eligible patients, 654 patients (71\%) underwent tracheostomy, with 136 patients (15\%) receiving early tracheostomy. Overall, the median time from initiation of MV to tracheostomy was 12 days (interquartile range 8-15 days). After stabilized inverse probability of treatment weighting, early tracheostomy was not associated with lower in-hospital mortality (risk difference $0.4 \%$; $95 \%$ confidence interval -5.6 to $6.7 \%$ ) compared with patients without early tracheostomy. There were no significant differences in 28-day mortality (risk difference - 1.3\%; 95\% confidence interval -3.5 to $0.9 \%$ ) and incidence of nosocomial pneumonia (risk difference $-2.6 \%$; $95 \%$ confidence

\footnotetext{
*Correspondence: nyone139@gmail.com

${ }^{1}$ Department of Clinical Epidemiology and Health Economics, School of Public Health, The University of Tokyo, 7-3-1 Hongo, Bunkyo-ku, Tokyo 1130033, Japan

Full list of author information is available at the end of the article
}

\section{实 Springer}


interval -9.1 to $4.2 \%$ ) between the two groups. None of the other secondary outcomes differed significantly between the groups.

Conclusions: Early tracheostomy was not significantly associated with decreased mortality or morbidity in patients with GBS requiring MV for more than 1 week.

Keywords: Guillain-Barré syndrome, Tracheostomy, Pneumonia, Hospital mortality, Outcome, Mechanical ventilation

\section{Introduction}

Respiratory failure is the most serious manifestation of Guillain-Barré syndrome (GBS), and mechanical ventilation (MV) is required in 30\% of severely ill GBS patients [1]. However, even with immunotherapy and general supportive care, reported in-hospital mortality rates were $10.4-16.8 \%$ in GBS patients needing MV [1-4].

Most patients with GBS receiving MV eventually require a tracheostomy because of the high risk of prolonged MV [5-11]. However, although mechanically ventilated patients with GBS are regarded as candidates for early tracheostomy [12-14], information on its benefits in these patients is lacking.

Two recent meta-analyses demonstrated the superiority of early compared with late tracheostomy in critically ill patients $[15,16]$ and indicated that early tracheostomy may be associated with reduced mortality [15] and a lower incidence of nosocomial pneumonia [16]. It may also offer clinical benefits in selected groups of patients, such as those with acute brain injury [17], spinal cord injury [18], stroke [19], or peripheral nerve disorders [12]. However, there remain unanswered questions regarding which patients are likely to benefit from early tracheostomy.

There may be some advantages of early tracheostomy in mechanically ventilated patients with GBS. The pathophysiological mechanisms of neuromuscular respiratory failure in GBS patients, characterized by bulbar palsy and respiratory muscle paralysis [20], differ from those in other critically ill patients. Specifically, bulbar palsy and respiratory muscle paralysis induce acute respiratory failure through a combination of poor airway protection, inadequate secretion clearance, and hypoventilation [20]. These entities contribute to a high incidence of respiratory complications, including atelectasis and pneumonia, as a major cause of death [2,21-23]. Early tracheostomy may thus provide potentially effective supportive care as well as a reduction in respiratory complications in GBS patients, with potentially favorable outcomes.

However, to the best of our knowledge, no previous studies have examined the effects of early tracheostomy in patients with GBS, possibly because of the difficulty in recruiting enough eligible patients. We therefore performed a retrospective comparison of early and non-early tracheostomy in patients with GBS who received MV for more than 1 week. The aim of this study was to evaluate the effects of early tracheostomy on mortality and the occurrence of nosocomial pneumonia in mechanically ventilated patients with GBS.

\section{Materials and Methods Data Source}

We performed a retrospective observational study using data from the nationwide Japanese Diagnosis Procedure Combination (DPC) inpatient database. Because all data were anonymized, the institutional review board of The University of Tokyo approved this study without the need for individual patient consent.

The DPC database comprises inpatient administrative claims and discharge abstract data from more than 1200 acute-care hospitals in Japan. It contains clinical data for each patient with high precision and validity [24]. The database represents around $50 \%$ of all acute admissions and covers all 82 academic hospitals and over $90 \%$ of all tertiary care emergency hospitals in Japan. The participating hospitals in the DPC database are distributed across all 47 prefectures in Japan.

The database contains the following information: unique hospital identifiers; age; sex; admission and discharge dates; body weight and height; main diagnosis, primary diagnosis at admission, comorbidities at admission, and post-admission complications recorded with the International Classification of Diseases, Tenth Revision (ICD-10) codes and Japanese text; drugs prescribed; devices used; surgical and non-surgical procedures conducted; intensive care unit (ICU) admission; length of stay; and discharge status. Complications arising after admission are clearly differentiated from comorbidities already present at the time of admission. Other details of the database have been described elsewhere [25].

\section{Patient Selection}

We identified mechanically ventilated patients with GBS (ICD-10 code: G610) in the DPC database from July 1, 2010, to March 31, 2018. We included patients aged 18 years or older who initiated MV within the first week of admission and who received MV for more than 1 week, and whose confirmed main diagnosis in Japanese text was 'Guillain-Barré syndrome.' We assumed that a requirement for MV management within the first week 
of admission was representative of GBS-associated neuromuscular respiratory failure [26]. The exclusion criteria were as follows: (1) patients with a Japanese text-based main diagnosis of 'suspected' GBS or variants of GBS (Miller Fisher syndrome and Bickerstaff's brain-stem encephalitis); (2) patients who also had chronic inflammatory demyelinating polyneuropathy (ICD-10 code: G618); (3) patients who initiated MV on admission day 8 or later; (4) patients who were transferred from other hospitals after the initiation of $M V$, because of a lack of information on the duration of MV; (5) patients who died within 7 days after MV (to avoid immortal time bias) [27]; and (6) patients who were weaned from MV or discharged within 7 days after MV or who received tracheostomy on day 28 or later (to create a more homogeneous population and avoid biases related to outlier patients) [12].

We defined early tracheostomy as tracheostomy within 7 days after MV and non-early tracheostomy as tracheostomy thereafter (late tracheostomy) or no tracheostomy. We chose this cutoff point in advance based on previous studies $[28,29]$ and the median times from MV initiation to tracheostomy in several observational studies of GBS patients (8-14 days) $[5,8,9]$.

\section{Covariates and Outcomes}

We compared the following covariates between the early and non-early tracheostomy groups: age [30]; sex; body mass index $\left(\mathrm{kg} / \mathrm{m}^{2}\right)$; Japan Coma Scale status at admission [31]; Charlson comorbidity index score [2, 4, 32]; chronic pulmonary disease as a comorbidity at admission [5, 7]; pneumonia (ICD-10 code J10-J18 or J69) as a complication at admission [6]; hyponatremia (ICD-10 codes E222 and E871) as a complication at admission [33, 34]; neurological presentation at admission (bulbar palsy [ICD-10 codes G12, G521, G522, G523, R13, and R47] and autonomic dysfunction [ICD-10 codes G90, H570, I10, I49, I95, K56, K59, L74, N39, R00, R15, R32, R33, R39, and R61]) [35, 36]; ambulance use; referral from other hospitals; treatment year [1-4]; number of days from hospital admission to MV initiation [6]; ICU admission until the day of MV initiation; treatments until the day of MV initiation [procedures and monitoring (invasive arterial pressure monitoring, central venous catheter insertion, $\mathrm{CO}_{2}$ monitoring, deep vein thrombosis prophylaxis, and chest compression and/or defibrillation), medical treatments (vasopressors, intravenous antihypertensive drugs, antiarrhythmic drugs, insulin, antiulcer drugs, antibiotic drugs, heparin, and enteral nutrition), and starting immunotherapy (plasma exchange, intravenous immunoglobulin (IVIg), intravenous corticosteroids, and none)].
Patients were categorized into three age groups: $\leq 40$, 41-60, and $>60$ years [30]. According to the World Health Organization definition, body mass index was categorized as $<18.50,18.50-24.99,25.00-29.99, \geq 30.00 \mathrm{~kg} /$ $\mathrm{m}^{2}$, and missing. According to the Japan Coma Scale status, which correlates well with the Glasgow Coma Scale [31], patients were categorized as alert, dizzy, somnolent, or comatose. A Charlson comorbidity index, as a weighted composite score of 12 different comorbidities, was scored using the diagnoses for each patient and categorized as $0,1,2$, or $\geq 3$ [32].

The primary outcome was in-hospital mortality. The secondary outcomes were 28-day mortality, nosocomial pneumonia, length of hospital stay, length of ICU stay, duration of MV, duration of sedation, duration of analgesia, duration of delirium, and total hospitalization costs. We extracted information on nosocomial pneumonia using recorded ICD-10 codes J13-J18 [37]. Duration of sedation was defined as duration of use of propofol, midazolam, and dexmedetomidine. Duration of analgesia was defined as duration of use of morphine and fentanyl. Duration of delirium was defined as duration of use of haloperidol, olanzapine, quetiapine, clozapine, and risperidone.

\section{Statistical Analyses}

We performed stabilized inverse probability of treatment weighting (IPTW) analyses to account for differences in baseline covariates between patients in the early and non-early tracheostomy groups. Stabilized IPTW is a propensity score-based method to adjust for measured potential confounding factors, which creates a pseudodataset by preserving sample size [38]. Propensity scores for early tracheostomy were calculated using a logistic regression model. The independent variables were: age; sex; body mass index; Japan Coma Scale status at admission; Charlson comorbidity index score; comorbidity of chronic pulmonary disease; complication of pneumonia at admission; complication of hyponatremia at admission; neurological presentation at admission; ambulance use; referral from other hospitals; treatment year; days from hospital admission to MV initiation; ICU admission until the day of MV initiation; and treatments until the day of MV initiation. We used the propensity scores to derive stabilized weights, which maintains appropriate type I error by preserving the sample size in the pseudodataset [38]. To assess the performances before and after stabilized IPTW, we compared the covariates using absolute standardized differences, with differences $>10 \%$ regarded as an imbalance between the two groups [39]. Stabilized IPTW estimates the average treatment effects over a marginal distribution of measured covariates in the matched cohort. 
In the current study, we expected wide between-hospital variation in the timing of tracheostomy [28]. We therefore used generalized linear models with clusterrobust standard errors treating each hospital as a cluster for comparisons of the primary and secondary outcomes. Risk differences, risk ratios, and their 95\% confidence intervals (CIs) were calculated for the outcomes. These estimates were obtained through the generalized linear models with identity (for difference) and log (for ratio) link functions. To address the issue of competing outcomes, length of hospital stay, length of ICU stay, duration of MV, duration of sedation, duration of analgesia, duration of delirium, and total hospitalization costs were evaluated for the survivors.

We performed a sensitivity analysis excluding patients who did not undergo tracheostomy. Risk differences, risk ratios, and 95\% CIs were calculated.

Categorical variables were reported as $n$ (\%) and continuous variables as median and interquartile range (IQR). All statistical analyses were performed using STATA/MP 16.0 software (StataCorp, College Station, TX, USA).

\section{Results}

The patient selection procedure is shown in Fig. 1. During the 93-month study period, we identified 1813 GBS patients who received MV, of whom 919 were eligible for the current study. The patients were divided into an early tracheostomy group $(n=136)$ and a non-early tracheostomy group $(n=783)$. The non-early tracheostomy group comprised a late tracheostomy group $(n=518)$ and a no tracheostomy group $(n=265)$. Overall, 654 patients (71\%) underwent tracheostomy. The median time from MV initiation to tracheostomy was 6 days (IQR 4-7 days) in the early tracheostomy group, 13 days (IQR 10-16 days) in the late tracheostomy group, and 12 days (IQR 8-15 days) in the overall tracheostomy group.

The baseline characteristics and treatment before and after stabilized IPTW are given in Tables 1 and 2. Compared with the non-early tracheostomy group before stabilized IPTW, patients in the early tracheostomy group were more likely to have pneumonia and hyponatremia as complications, be referred from other hospitals, be admitted to the ICU until the day of MV initiation, receive vasopressors and enteral nutrition, and start IVIg until the day of MV initiation. After stabilized IPTW, the patient characteristics were well-balanced between the groups, with absolute standardized differences of $<10 \%$ for all covariates.

The overall in-hospital mortality was 7.4\% (68/919). In-hospital mortality in the early, late, and no tracheostomy groups was $5.9 \%(8 / 136), 6.4 \%(33 / 518)$, and

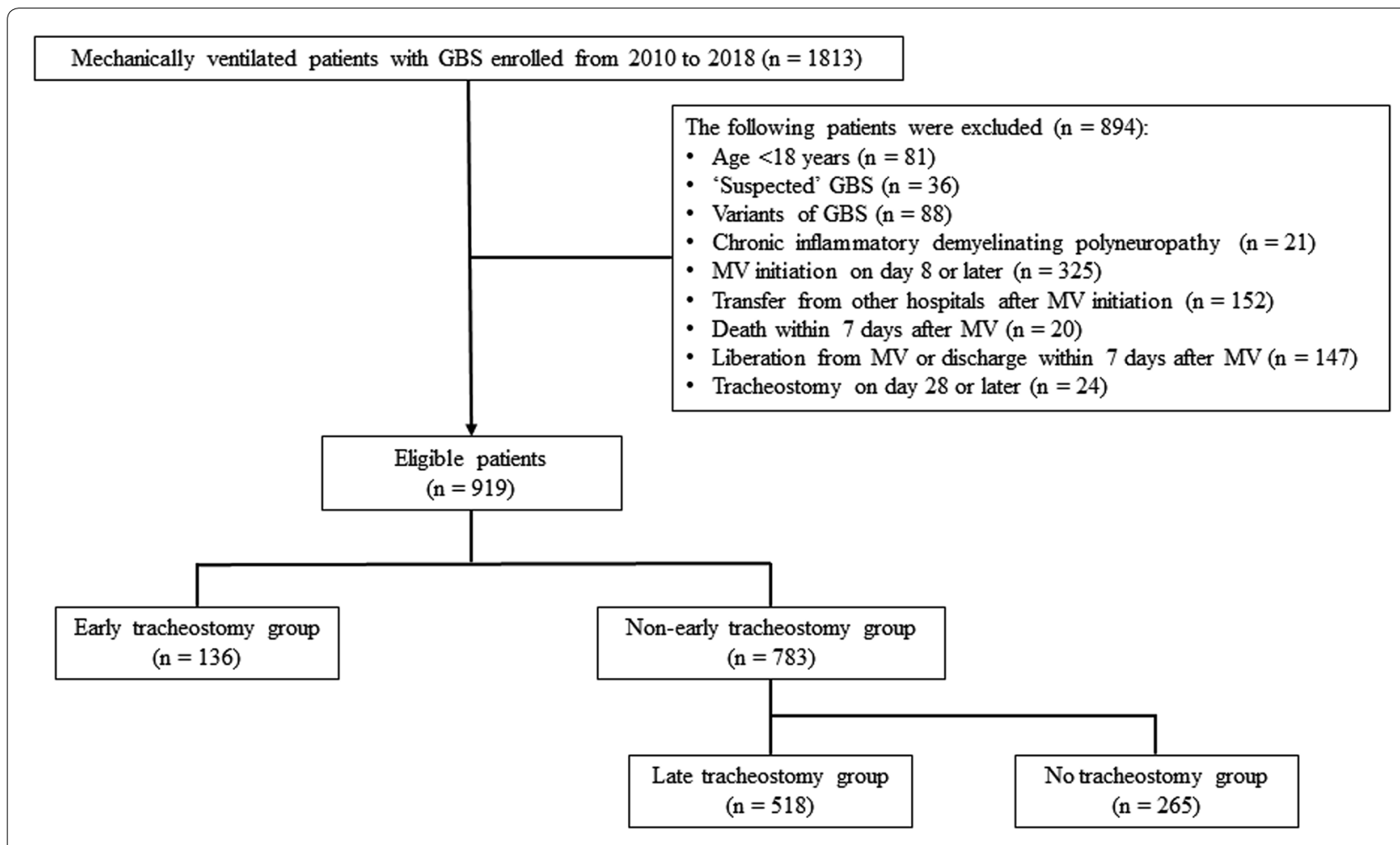

Fig. 1 Flowchart of patient selection. GBS Guillain-Barré syndrome; MV mechanical ventilation 
Table 1 Baseline characteristics of patients before and after stabilized IPTW

\begin{tabular}{|c|c|c|c|c|c|c|}
\hline \multirow[t]{2}{*}{ Covariates } & \multicolumn{3}{|l|}{ Before stabilized IPTW } & \multicolumn{3}{|l|}{ After stabilized IPTW } \\
\hline & $\begin{array}{l}\text { Early tracheostomy } \\
(n=136)\end{array}$ & $\begin{array}{l}\text { Non-early tracheos- } \\
\text { tomy }(n=783)\end{array}$ & ASD & $\begin{array}{l}\text { Early tracheostomy } \\
(n=135)\end{array}$ & $\begin{array}{l}\text { Non-early tracheos- } \\
\text { tomy }(n=784)\end{array}$ & ASD \\
\hline \multicolumn{7}{|l|}{ Age (years) } \\
\hline$\leq 40$ & $24(17.6)$ & $157(20.1)$ & 6.1 & $22(16.3)$ & $154(19.6)$ & 8.3 \\
\hline $41-60$ & $41(30.1)$ & $214(27.3)$ & 6.2 & $44(32.6)$ & $218(27.8)$ & 9.8 \\
\hline$>60$ & $71(52.2)$ & $412(52.6)$ & 0.8 & $69(51.1)$ & $412(52.6)$ & 2.6 \\
\hline Sex (male) & $81(59.6)$ & $436(55.7)$ & 7.8 & $74(54.8)$ & $441(56.3)$ & 2.5 \\
\hline \multicolumn{7}{|l|}{ Body mass index $\left(\mathrm{kg} / \mathrm{m}^{2}\right)$} \\
\hline$<18.50$ & $19(14.0)$ & $124(15.8)$ & 5.2 & $22(16.3)$ & $122(15.6)$ & 1.3 \\
\hline $18.50-24.99$ & $82(60.3)$ & $433(55.3)$ & 10.1 & $77(57.0)$ & $439(56.0)$ & 2.9 \\
\hline $25.00-29.99$ & $20(14.7)$ & $107(13.7)$ & 3.0 & $16(11.9)$ & $108(13.8)$ & 6.1 \\
\hline$\geq 30.00$ & $6(4.4)$ & $34(4.3)$ & 0.3 & $6(4.4)$ & $34(4.3)$ & 1.1 \\
\hline Missing data & $9(6.6)$ & $85(10.9)$ & 15.1 & $14(10.4)$ & $80(10.2)$ & 1.0 \\
\hline \multicolumn{7}{|c|}{ Japan Coma Scale status at admission } \\
\hline Alert & $99(72.8)$ & $553(70.6)$ & 4.8 & $93(68.9)$ & $556(70.9)$ & 3.7 \\
\hline Dizziness & $26(19.1)$ & $129(16.5)$ & 6.9 & $26(19.3)$ & $133(17.0)$ & 6.3 \\
\hline Somnolence & $6(4.4)$ & $53(6.8)$ & 10.3 & $6(4.4)$ & $50(6.4)$ & 8.3 \\
\hline Coma & $5(3.7)$ & $48(6.1)$ & 11.4 & $9(6.7)$ & $45(5.7)$ & 4.7 \\
\hline \multicolumn{7}{|l|}{ Charlson comorbidity index } \\
\hline 0 & $109(80.1)$ & $597(76.2)$ & 9.5 & $108(80.0)$ & $603(76.9)$ & 7.3 \\
\hline 1 & $8(5.9)$ & $51(6.5)$ & 2.6 & $6(4.4)$ & $50(6.4)$ & 7.3 \\
\hline 2 & $14(10.3)$ & $109(13.9)$ & 11.1 & $15(11.1)$ & $105(13.4)$ & 7.3 \\
\hline$\geq 3$ & $5(3.7)$ & $26(3.3)$ & 1.9 & $6(4.4)$ & $27(3.4)$ & 5.5 \\
\hline Chronic pulmonary disease & $5(3.7)$ & $33(4.2)$ & 2.8 & $6(4.4)$ & $32(4.1)$ & 1.2 \\
\hline \multicolumn{7}{|l|}{ Complications at admission } \\
\hline Pneumonia & $45(33.1)$ & $203(25.9)$ & 15.7 & $35(25.9)$ & $211(26.9)$ & 1.5 \\
\hline Hyponatremia & $5(3.7)$ & $13(1.7)$ & 12.5 & $2(1.5)$ & $15(1.9)$ & 1.3 \\
\hline \multicolumn{7}{|c|}{ Neurological presentations at admission } \\
\hline Bulbar palsy & $24(17.6)$ & $117(14.9)$ & 7.3 & $20(14.8)$ & $120(15.3)$ & 2.1 \\
\hline Autonomic dysfunction & $37(27.2)$ & $201(25.7)$ & 3.5 & $37(27.4)$ & $204(26.0)$ & 2.6 \\
\hline Ambulance use & $69(50.7)$ & $429(54.8)$ & 8.6 & $78(57.8)$ & $426(54.3)$ & 6.2 \\
\hline Referral from other hospitals & $81(59.6)$ & $403(51.5)$ & 15.7 & $71(52.6)$ & $413(52.7)$ & 1.0 \\
\hline \multicolumn{7}{|l|}{ Treatment year } \\
\hline 2010 & 9 (6.6) & $49(6.3)$ & 1.5 & $8(5.9)$ & $49(6.3)$ & 1.3 \\
\hline 2011 & $12(8.8)$ & $88(11.2)$ & 8.0 & $15(11.1)$ & $85(10.8)$ & 2.1 \\
\hline 2012 & $15(11.0)$ & $100(12.8)$ & 5.4 & $18(13.3)$ & $99(12.6)$ & 3.1 \\
\hline 2013 & $11(8.1)$ & $65(8.3)$ & 0.8 & $9(6.7)$ & $64(8.2)$ & 6.0 \\
\hline 2014 & $14(10.3)$ & $102(13.0)$ & 8.5 & $18(13.3)$ & $99(12.6)$ & 1.7 \\
\hline 2015 & 24 (17.6) & $126(16.1)$ & 4.2 & $24(17.8)$ & $128(16.3)$ & 3.1 \\
\hline 2016 & 27 (19.9) & $136(17.4)$ & 6.4 & $23(17.0)$ & $139(17.7)$ & 2.6 \\
\hline 2017 & 24 (17.6) & $117(14.9)$ & 7.3 & $20(14.8)$ & $121(15.4)$ & 1.6 \\
\hline
\end{tabular}

Data presented as $n$ (\%)

ASD absolute standardized difference, IPTW inverse probability of treatment weighting

$10 \%(27 / 265)$, respectively. The median duration of MV among survivors was 30 days (IQR 15-68 days), 39 days (IQR 22-68 days), and 13 days (IQR 10-19) in the early, late, and no tracheostomy groups, respectively. The outcomes before and after stabilized IPTW are given in Table 3. There was no significant difference in in-hospital mortality between the early and non-early tracheostomy groups after stabilized IPTW (risk difference, $0.4 \%$; $95 \%$ CI -5.6 to $6.7 \%$ ). Similarly, there was no significant difference in 28-day mortality 
Table 2 Days from hospital admission to initiating MV, and treatment covariates until day of initiation of MV before and after stabilized IPTW

\begin{tabular}{|c|c|c|c|c|c|c|}
\hline \multirow[t]{2}{*}{ Covariates } & \multicolumn{3}{|c|}{ Before stabilized IPTW } & \multicolumn{3}{|c|}{ After stabilized IPTW } \\
\hline & $\begin{array}{l}\text { Early tracheos- } \\
\text { tomy }(n=136)\end{array}$ & $\begin{array}{l}\text { Non-early tracheos- } \\
\text { tomy }(n=783)\end{array}$ & ASD & $\begin{array}{l}\text { Early tracheos- } \\
\text { tomy }(n=135)\end{array}$ & $\begin{array}{l}\text { Non-early tracheos- } \\
\text { tomy }(n=784)\end{array}$ & ASD \\
\hline \multicolumn{7}{|c|}{ Days from hospital admission to initiating MV } \\
\hline 1 & $38(27.9)$ & $215(27.5)$ & 1.1 & $42(31.1)$ & $216(27.6)$ & 8.1 \\
\hline 2 & $34(25.0)$ & $220(28.1)$ & 7.0 & $39(28.9)$ & $217(27.7)$ & 2.2 \\
\hline 3 & $33(24.3)$ & $149(19.0)$ & 12.7 & $25(18.5)$ & $155(19.8)$ & 3.8 \\
\hline 4 & $12(8.8)$ & $78(10.0)$ & 3.9 & $13(9.6)$ & $77(9.8)$ & 0.7 \\
\hline 5 & $8(5.9)$ & $58(7.4)$ & 6.1 & $8(5.9)$ & $56(7.1)$ & 5.3 \\
\hline 6 & $8(5.9)$ & $35(4.5)$ & 6.4 & $6(4.4)$ & $36(4.6)$ & 0.8 \\
\hline 7 & $3(2.2)$ & $28(3.6)$ & 8.2 & $2(1.5)$ & $26(3.3)$ & 9.4 \\
\hline ICU admission until day of MV initiation & $104(76.5)$ & $462(59.0)$ & 38.0 & $87(64.4)$ & $483(61.6)$ & 6.2 \\
\hline \multicolumn{7}{|c|}{ Procedures and monitoring until day of MV initiation } \\
\hline Invasive arterial pressure monitoring & $58(42.6)$ & $259(33.1)$ & 19.8 & $51(37.8)$ & $272(34.7)$ & 7.0 \\
\hline Central venous catheter insertion & $49(36.0)$ & $248(31.7)$ & 9.2 & $40(29.6)$ & $253(32.3)$ & 5.0 \\
\hline $\mathrm{CO}_{2}$ monitoring & $35(25.7)$ & $114(14.6)$ & 28.1 & $21(15.6)$ & $127(16.2)$ & 2.0 \\
\hline Deep vein thrombosis prophylaxis & $58(42.6)$ & $258(33.0)$ & 20.1 & $49(36.3)$ & $270(34.4)$ & 4.4 \\
\hline Chest compression/defibrillation & $4(2.9)$ & $17(2.2)$ & 4.9 & $3(2.2)$ & $18(2.3)$ & 2.1 \\
\hline \multicolumn{7}{|c|}{ Medical treatments until the day of MV initiation } \\
\hline Vasopressors & $36(26.5)$ & $170(21.7)$ & 11.1 & $28(20.7)$ & $176(22.4)$ & 3.6 \\
\hline Intravenous antihypertensive drugs & $21(15.4)$ & $93(11.9)$ & 10.4 & $17(12.6)$ & $97(12.4)$ & 0.7 \\
\hline Antiarrhythmic drugs & $10(7.4)$ & $53(6.8)$ & 2.3 & $7(5.2)$ & $54(6.9)$ & 5.5 \\
\hline Insulin & $28(20.6)$ & $108(13.8)$ & 18.0 & $18(13.3)$ & $116(14.8)$ & 3.3 \\
\hline Antiulcer drugs & $92(67.6)$ & $527(67.3)$ & 0.7 & $91(67.4)$ & $528(67.3)$ & 0.6 \\
\hline Antibiotic drugs & $77(56.6)$ & $430(54.9)$ & 3.4 & $71(52.6)$ & $431(55.0)$ & 4.8 \\
\hline Heparin & $68(50.0)$ & $348(44.4)$ & 11.1 & $55(40.7)$ & $354(45.2)$ & 8.0 \\
\hline Enteral nutrition & $36(26.5)$ & $160(20.4)$ & 14.3 & $29(21.5)$ & $168(21.4)$ & 0.4 \\
\hline \multicolumn{7}{|l|}{ Immunotherapy until day of MV initiation } \\
\hline Plasma exchange & $11(8.1)$ & $53(6.8)$ & 5.0 & $7(5.2)$ & $54(6.9)$ & 7.0 \\
\hline IVlg & $113(83.1)$ & $541(69.1)$ & 33.2 & $97(71.9)$ & $558(71.2)$ & 2.4 \\
\hline Intravenous corticosteroids & $37(27.2)$ & $216(27.6)$ & 0.9 & $42(31.1)$ & $216(27.6)$ & 8.5 \\
\hline None & $12(8.8)$ & $145(18.5)$ & 28.5 & $22(16.3)$ & $134(16.7)$ & 2.9 \\
\hline
\end{tabular}

Data presented as $n$ (\%)

ASD absolute standardized difference, ICU intensive care unit, IPTW inverse probability of treatment weighting, IVIg intravenous immunoglobulin, $M V$ mechanical ventilation

between the two groups after stabilized IPTW (risk difference $-1.3 \%$; $95 \% \mathrm{CI}-3.5$ to $0.9 \%$ ). The proportions of patients with nosocomial pneumonia were similar in the two groups after stabilized IPTW (risk difference $-2.6 \%$; $95 \%$ CI -9.1 to $4.2 \%$ ). No significant differences in the other secondary outcomes were detected between the two groups after stabilized IPTW.

The results of the sensitivity analysis restricted to patients who underwent tracheostomy were compatible with those of the main analysis (Table 4).

\section{Discussion}

The current study compared the clinical outcomes between mechanically ventilated patients with GBS with and without early tracheostomy, using a Japanese nationwide inpatient database. We found no significant differences in in-hospital mortality, 28-day mortality, incidence of nosocomial pneumonia, length of hospital stay, length of ICU stay, duration of MV, duration of sedation, duration of analgesia, duration of delirium, and total hospitalization costs between the two groups. 
Table 3 Patient outcomes before and after stabilized IPTW

\begin{tabular}{|c|c|c|c|c|c|c|}
\hline \multirow[t]{2}{*}{ Outcomes } & \multicolumn{2}{|c|}{ Before stabilized IPTW } & \multicolumn{4}{|c|}{ After stabilized IPTW } \\
\hline & $\begin{array}{l}\text { Early tracheos- } \\
\text { tomy }(n=136)\end{array}$ & $\begin{array}{l}\text { Non-early trache- } \\
\text { ostomy }(n=783)\end{array}$ & $\begin{array}{l}\text { Early tracheos- } \\
\text { tomy }(n=135)\end{array}$ & $\begin{array}{l}\text { Non-early trache- } \\
\text { ostomy }(n=784)\end{array}$ & $\begin{array}{l}\text { Risk difference } \\
(95 \% \mathrm{Cl})\end{array}$ & Risk ratio $(95 \% \mathrm{Cl})$ \\
\hline In-hospital mortality & $8(5.9)$ & $60(7.7)$ & $11(8.1)$ & $59(7.5)$ & $0.4(-5.6$ to 6.7$)$ & 1.05 (0.48 to 2.27) \\
\hline 28-day mortality & $2(1.5)$ & $21(2.7)$ & $2(1.5)$ & $21(2.7)$ & $-1.3(-3.5$ to 0.9$)$ & 0.51 (0.12 to 2.15$)$ \\
\hline $\begin{array}{l}\text { Nosocomial pneu- } \\
\text { monia }\end{array}$ & $18(13.2)$ & $123(15.7)$ & $18(13.3)$ & $123(15.7)$ & $-2.6(-9.1$ to 4.2$)$ & 0.83 (0.50 to 1.39 ) \\
\hline $\begin{array}{l}\text { Length of hospital } \\
\text { stay* }\end{array}$ & $67(54-125)$ & $65(48-113)$ & $68(54-126)$ & $64(48-113)$ & 9.7 ( -8.3 to 27.6$)$ & 1.10 (0.92 to 1.33$)$ \\
\hline Length of ICU stay* & $13(8-14)$ & $14(12-14)$ & $13(8-14)$ & $14(12-14)$ & $-0.2(-3.4$ to 3.0$)$ & 0.99 (0.79 to 1.23) \\
\hline Duration of $\mathrm{MV}^{*}$ & $30(15-68)$ & $28(14-55)$ & $31(16-67)$ & $28(14-54)$ & $11.2(-1.6$ to 24.1$)$ & 1.24 (0.99 to 1.57 ) \\
\hline $\begin{array}{l}\text { Duration of seda- } \\
\text { tion* }\end{array}$ & $9(6-17)$ & $14(10-22)$ & $9(5-17)$ & $14(10-22)$ & -1.0 (-6.6 to 4.7) & 0.95 (0.73 to 1.26$)$ \\
\hline $\begin{array}{l}\text { Duration of anal- } \\
\text { gesia* }\end{array}$ & $6(3-11)$ & $10(4-16)$ & $6(3-10)$ & $11(4-16)$ & $-3.2(-7.8$ to 1.4$)$ & 0.76 (0.48 to 1.19$)$ \\
\hline $\begin{array}{l}\text { Duration of } \\
\text { delirium* }\end{array}$ & $12(2-38)$ & $11(1-35)$ & $9(1-35)$ & $12(1-36)$ & $-5.2(-14.3$ to 3.9$)$ & 0.79 (0.52 to 1.22$)$ \\
\hline $\begin{array}{l}\text { Total hospitalization } \\
\text { costs* }\end{array}$ & $\begin{array}{l}50,924(38,087- \\
68,367)\end{array}$ & $\begin{array}{l}46,803(35,300- \\
64,833)\end{array}$ & $\begin{array}{l}47,918(35,858- \\
66,417)\end{array}$ & $\begin{array}{l}47,161(35,612- \\
65,094)\end{array}$ & $\begin{array}{l}2758(-4923 \text { to } \\
10,438)\end{array}$ & 1.08 (0.94 to 1.24$)$ \\
\hline
\end{tabular}

Data presented as $n$ (\%) or median (interquartile range)

*Length of hospital stay (days), length of ICU stay (days), duration of MV (days), duration of sedation (days), duration of analgesia (days), duration of delirium (days), and total hospitalization costs (US\$) were analyzed among the survivors

$\mathrm{Cl}$ confidence interval, ICU intensive care unit, IPTW inverse probability of treatment weighting, $M V$ mechanical ventilation

Table 4 Outcomes of sensitivity analyses before and after stabilized IPTW, restricted to patients who underwent tracheostomy

\begin{tabular}{|c|c|c|c|c|c|c|}
\hline \multirow[t]{2}{*}{ Outcomes } & \multicolumn{2}{|c|}{ Before stabilized IPTW } & \multicolumn{4}{|c|}{ After stabilized IPTW } \\
\hline & $\begin{array}{l}\text { Early tracheos- } \\
\text { tomy }(n=136)\end{array}$ & $\begin{array}{l}\text { Late tracheos- } \\
\text { tomy }(n=518)^{*}\end{array}$ & $\begin{array}{l}\text { Early tracheos- } \\
\text { tomy }(n=135)\end{array}$ & $\begin{array}{l}\text { Late tracheos- } \\
\text { tomy }(n=519)^{*}\end{array}$ & $\begin{array}{l}\text { Risk difference } \\
(95 \% \mathrm{CI})\end{array}$ & Risk ratio $(95 \% \mathrm{Cl})$ \\
\hline In-hospital mortality & $8(5.9)$ & $33(6.4)$ & $12(8.9)$ & $32(6.2)$ & $2.3(-4.3$ to 9.4$)$ & 1.37 (0.61 to 3.12) \\
\hline 28-day mortality & $2(1.5)$ & $4(0.8)$ & $2(1.5)$ & $4(0.8)$ & $0.7(-1.6$ to 3.1$)$ & 1.90 (0.34 to 10.46) \\
\hline $\begin{array}{l}\text { Nosocomial pneu- } \\
\text { monia }\end{array}$ & $18(13.2)$ & $91(17.6)$ & $18(13.3)$ & $92(17.7)$ & -4.0 (- 10.8 to 3.3$)$ & 0.77 (0.46 to 1.29) \\
\hline $\begin{array}{l}\text { Length of hospital } \\
\text { stay }^{\dagger}\end{array}$ & $67(54-125)$ & $81(56-132)$ & $68(54-126)$ & $80(56-131)$ & $-5.8(-22.0$ to 10.5$)$ & 0.94 (0.80 to 1.11) \\
\hline Length of ICU stay ${ }^{\dagger}$ & $13(8-14)$ & $14(14-14)$ & $13(8-14)$ & $14(14-14)$ & $-1.1(-4.0$ to 1.8$)$ & 0.93 (0.76 to 1.13 ) \\
\hline Duration of $\mathrm{MV}^{\dagger}$ & $30(15-68)$ & $39(22-68)$ & $32(15-67)$ & $39(22-68)$ & $-0.5(-12.6$ to 11.6$)$ & 0.99 (0.80 to 1.23 ) \\
\hline $\begin{array}{l}\text { Duration of } \\
\text { sedation }^{\dagger}\end{array}$ & $9(6-17)$ & $16(12-24)$ & $9(5-17)$ & $16(12-24)$ & -4.0 ( -9.9 to 1.8$)$ & 0.84 (0.63 to 1.10$)$ \\
\hline $\begin{array}{l}\text { Duration of } \\
\text { analgesia }^{\dagger}\end{array}$ & $6(3-11)$ & $11(3-17)$ & $6(3-10)$ & $11(3-17)$ & $-4.2(-8.7$ to 0.2$)$ & 0.70 (0.45 to 1.07$)$ \\
\hline $\begin{array}{l}\text { Duration of } \\
\text { delirium }^{\dagger}\end{array}$ & $12(2-38)$ & $15(1-40)$ & $11(1-35)$ & $14(1-40)$ & $-6.4(-16.8$ to 3.9$)$ & 0.77 (0.50 to 1.19 ) \\
\hline $\begin{array}{l}\text { Total hospitalization } \\
\text { costs }^{\dagger}\end{array}$ & $\begin{array}{l}50,924(38,087- \\
68,367)\end{array}$ & $\begin{array}{l}53,597(42,921- \\
73,112)\end{array}$ & $\begin{array}{l}48,074(35,993- \\
66,417)\end{array}$ & $\begin{array}{l}53,872(43,217- \\
73,426)\end{array}$ & $\begin{array}{l}-3774(-11,337 \text { to } \\
3788)\end{array}$ & 0.94 (0.83 to 1.07) \\
\hline
\end{tabular}

Data presented as $n$ (\%) or median (interquartile range)

*Late tracheostomy indicates procedure done within 8-27 days of mechanical ventilation

+ Length of hospital stay (days), length of ICU stay (days), duration of MV (days), duration of sedation (days), duration of analgesia (days), duration of delirium (days), and total hospitalization costs (US\$) were analyzed among the survivors

$\mathrm{Cl}$ confidence interval, ICU intensive care unit, IPTW inverse probability of treatment weighting, MV mechanical ventilation 
In the current study, patients who received late tracheostomy or did not receive tracheostomy were analyzed together as a non-early tracheostomy group, because we assumed that the latter were potential candidates for tracheostomy. While the decision to place a tracheostomy in critically ill patients generally depends on the expected length of required $\mathrm{MV}$, the clinical course, severity, and duration of respiratory failure in mechanically ventilated patients with GBS are highly diverse [29]. Although several studies have addressed the identification of predictors for prolonged MV in GBS patients [5, 9, 29, 40], only limited data are available to provide guidance for decision-making on early tracheostomy at the time of MV initiation. Furthermore, it is difficult to predict the extubation outcome, partly because of the difficulty in evaluating the severity of bulbar palsy and respiratory muscle paralysis during endotracheal tube placement [7, 41]. Currently, these uncertainties about the management of respiratory failure in GBS patients pose challenges for decision-making on performance of early tracheostomy.

Moreover, the potentially reversible nature of GBS can sometimes lead to avoidance of this invasive approach, even when patients receive prolonged MV. In fact, the overall no tracheostomy rate was $29 \%$ (265/919) in the current study. The median duration of MV among the survivors in the no tracheostomy group was 13 days (IQR 10-19 days), which may partly reflect the reality of clinical practice regarding prolonged endotracheal tube placement to prevent tracheostomy in Japan. Thus, a delay in decision-making for tracheostomy may result in successful weaning from MV without unnecessary injury.

In summary, it is difficult to predict the need for early tracheostomy in GBS patients at the time of MV initiation because of the heterogeneous nature and complexity of GBS. Therefore, the effects of early tracheostomy in GBS patients should be judged by those in patients at high risk for tracheostomy. Using stabilized IPTW analyses to adjust for multiple covariates until the day of MV initiation, we assumed that all GBS patients requiring MV for more than 1 week were potential candidates for tracheostomy. However, the decision on whether to perform tracheostomy in GBS patients has often been discretionary. To address the possibility that both relatively mild and fatal GBS patients were biased in the no tracheostomy group, we conducted a sensitivity analysis including only those who received tracheostomy.

Tracheostomy is commonly performed in critically ill patients, with the objective of improving respiratory mechanics, facilitating oral hygiene, promoting pulmonary hygiene, and improving patient comfort $[42,43]$. A previous small retrospective study in GBS patients $(n=54)$ showed that late tracheostomy on day 14 or later was associated with a higher incidence of ventilator-associated pneumonia [44]; however, the study was not designed to examine the effects of early tracheostomy.

Nationwide data on the timing of tracheostomy in patients with GBS are currently lacking. The current study using multicenter, real-world data from Japan showed that the median time to tracheostomy was 12 days, and only about $15 \%$ of GBS patients who received MV for more than 1 week underwent early tracheostomy within 7 days of MV. However, there was a trend toward early tracheostomy in GBS patients becoming more common during the study period. A similar trend was observed in the USA [45]. This trend may reflect the fact that physicians expect potential clinical benefits from early tracheostomy. We expected that mortality and the incidence of nosocomial pneumonia, as one of the major causes of death in GBS, would be reduced in the early tracheostomy group [2, 21-23]; however, the current study showed no significant association of early tracheostomy with either of these variables. Furthermore, all other secondary outcomes associated with expected effects of early tracheostomy showed no significant differences. The current sensitivity analysis restricted to patients who underwent tracheostomy did not change the main results. These results may be partly explained by difficulties with pulmonary hygiene under conditions of bulbar palsy and respiratory muscle paralysis during the progression phase irrespective of the use of early tracheostomy.

Recent guidelines from a French expert panel recommended performing tracheostomy for GBS patients based on weaning failure from MV and the lack of foot flexion at the end of immunotherapy [46]; however, this recommendation did not refer to the specific timing of tracheostomy. A retrospective observational study $(n=61)$, which was a rationale for the recommendation, reported a period of 8-10 days from ICU admission to the end of immunotherapy [9]. The results of the current study may thus support the proposal to perform tracheostomy in GBS patients judged to be at high risk for prolonged MV after the completion of immunotherapy.

Several limitations should be acknowledged when interpreting the results of the current study. First, the study had a retrospective observational design, and the assignment of early tracheostomy was not random. Unfortunately, because of data unavailability, the study could not account for pulmonary function tests, arterial blood gas analysis, ventilator settings, and reintubation events. Although we used stabilized IPTW analyses to control for possible measured confounders, our results may have been biased by unmeasured confounders regarding the severity of GBS-associated respiratory failure and GBS itself. However, time from hospital 
admission to MV initiation [6], neurological presentations at admission [36], and complications at admission $[6,33,34]$ were well balanced between mechanically ventilated patients with GBS with and without early tracheostomy. Second, we could not differentiate between percutaneous dilatational tracheostomy and surgical tracheostomy [47]. Moreover, we could not obtain data on tracheostomy-associated complications. Third, the incidence of nosocomial pneumonia may have been underestimated, because we identified a diagnosis of nosocomial pneumonia based on ICD-10 codes [37]. Fourth, it remains unclear whether early tracheostomy was associated with earlier transfer to a nursing or rehabilitation facility [45]. However, length of hospital stay did not differ significantly between the early and nonearly tracheostomy groups. Finally, although our sample size included a relatively large number of mechanically ventilated patients with GBS, the study may have been underpowered. Despite these limitations, to the best of our knowledge, this is the first study to focus on the effects of early tracheostomy on clinical outcomes in mechanically ventilated GBS patients.

\section{Conclusions}

This retrospective database study did not support an association between early tracheostomy and clinical outcomes, including mortality and incidence of nosocomial pneumonia, in GBS patients requiring MV for more than 1 week. Therefore, early tracheostomy within 7 days may not be recommended in GBS patients at high risk for prolonged MV.

\section{Author details \\ 1 Department of Clinical Epidemiology and Health Economics, School of Pub- lic Health, The University of Tokyo, 7-3-1 Hongo, Bunkyo-ku, Tokyo 1130033, Japan. ${ }^{2}$ Department of Health Services Research, Graduate School of Medi- cine, The University of Tokyo, Tokyo, Japan. ${ }^{3}$ Department of Health Policy and Informatics, Graduate School of Medicine, Tokyo Medical and Dental University, Tokyo, Japan.}

\begin{abstract}
Author Contributions
All authors of this research paper have directly participated in the planning, execution, or analysis of the study. NY, TJ, and HY were responsible for the statistical analyses and the first draft of the manuscript. All authors of this paper have read and approved the final version submitted. This manuscript complied with all instructions to authors. The contents of this manuscript have not been copyrighted or published previously and are not now under consideration for publication elsewhere.
\end{abstract}

\section{Source of Support}

$\mathrm{HY}$ and KF received grant support from the Japanese government. This work was supported in part by grants from the Ministry of Health, Labour and Welfare, Japan (19AA2007 and H30-Policy-Designated-004) and the Ministry of Education, Culture, Sports, Science and Technology, Japan (17H04141). The funders had no role in the execution of this study or interpretation of the results.

\section{Conflict of interest}

The authors declare that they have no conflict of interest.

\section{Ethical Approval and Informed Consent}

This study was based on a secondary analysis of the administrative data. Because all data were anonymized, the institutional review board of The University of Tokyo approved this study without the need for individual patient consent [Approval No. 3501-(1)].

\section{Publisher's Note}

Springer Nature remains neutral with regard to jurisdictional claims in published maps and institutional affiliations.

Published online: 14 April 2020

\section{References}

1. Ancona P, Bailey M, Bellomo R. Characteristics, incidence and outcome of patients admitted to intensive care unit with Guillain-Barré syndrome in Australia and New Zealand. J Crit Care. 2018;45:58-64.

2. Alshekhlee A, Hussain Z, Sultan B, et al. Guillain-Barré syndrome: incidence and mortality rates in US hospitals. Neurology. 2008;70:1608-13.

3. Damian MS, Ben-Shlomo Y, Howard R, et al. The effect of secular trends and specialist neurocritical care on mortality for patients with intracerebral haemorrhage, myasthenia gravis and Guillain-Barré syndrome admitted to critical care: an analysis of the Intensive Care National Audit \& Research Centre (ICNARC) national United Kingdom database. Intensive Care Med. 2013;39:1405-12.

4. Liou LS, Chung CH, Wu YT, et al. Epidemiology and prognostic factors of inpatient mortality of Guillain-Barré syndrome: a nationwide population study over 14 years in Asian country. J Neurol Sci. 2016;369:159-64.

5. Lawn ND, Wijdicks EF. Tracheostomy in Guillain-Barré syndrome. Muscle Nerve. 1999;22:1058-62.

6. Orlikowski D, Sharshar T, Porcher R, et al. Prognosis and risk factors of early onset pneumonia in ventilated patients with Guillain-Barré syndrome. Intensive Care Med. 2006;32:1962-9.

7. Nguyen TN, Badjatia N, Malhotra A, et al. Factors predicting extubation success in patients with Guillain-Barré syndrome. Neurocrit Care. 2006;5:230-4

8. Köhrmann M, Huttner HB, Nowe T, et al. Mechanical ventilation in Guillain-Barré syndrome: does age influence functional outcome? Eur Neurol. 2009;61:358-63.

9. Fourrier F, Robriquet L, Hurtevent JF, et al. A simple functional marker to predict the need for prolonged mechanical ventilation in patients with Guillain-Barré syndrome. Crit Care. 2011;15:R65.

10. Taylor CJ, Hirsch NP, Kullmann DM, et al. Changes in the severity and subtype of Guillain-Barré syndrome admitted to a specialist Neuromedical ICU over a 25 year period. J Neurol. 2017;264:564-9.

11. Schröder JB, Marian T, Muhle P, et al. Intubation, tracheostomy, and decannulation in patients with Guillain-Barré-syndrome-does dysphagia matter? Muscle Nerve. 2019;59:194-200.

12. Scales DC, Thiruchelvam D, Kiss A, et al. The effect of tracheostomy timing during critical illness on long-term survival. Crit Care Med. 2008;36:2547-57

13. Young D, Harrison DA, Cuthbertson $\mathrm{BH}$, et al. Effect of early vs late tracheostomy placement on survival in patients receiving mechanical ventilation: the TracMan randomized trial. JAMA. 2013;309:2121-9.

14. Diaz-Prieto A, Mateu A, Gorriz M, et al. A randomized clinical trial for the timing of tracheotomy in critically ill patients: factors precluding inclusion in a single center study. Crit Care. 2014;18:585.

15. Hosokawa K, Nishimura M, Egi M, et al. Timing of tracheotomy in ICU patients: a systematic review of randomized controlled trials. Crit Care. 2015;19:424.

16. Wang $R$, Pan $C$, Wang $X$, et al. The impact of tracheotomy timing in critically ill patients undergoing mechanical ventilation: a meta-analysis of randomized controlled clinical trials with trial sequential analysis. Heart Lung. 2019;48:46-54.

17. McCredie VA, Alali AS, Scales DC, et al. Effect of early versus late tracheostomy or prolonged intubation in critically ill patients with acute 
brain injury: a systematic review and meta-analysis. Neurocrit Care. 2017;26:14-25.

18. Ganuza JR, Garcia-Forcada A, Gambarrutta C, et al. Effect of technique and timing of tracheostomy in patients with acute traumatic spinal cord injury undergoing mechanical ventilation. J Spinal Cord Med. 2011;34:76-84.

19. Bösel J, Schiller P, Hook Y, et al. Stroke-related early tracheostomy versus prolonged orotracheal intubation in neurocritical care trial (SETPOINT): a randomized pilot trial. Stroke. 2013;44:21-8.

20. Racca F, Del Sorbo L, Mongini T, et al. Respiratory management of acute respiratory failure in neuromuscular diseases. Minerva Anestesiol. 2010;76:51-62.

21. Lawn ND, Wijdicks EF. Fatal Guillain-Barré syndrome. Neurology. 1999:52:635-8.

22. Chiò A, Cocito D, Leone M, et al. Guillain-Barré syndrome: a prospective, population-based incidence and outcome survey. Neurology. 2003;60:1146-50.

23. van den Berg B, Bunschoten C, van Doorn PA, et al. Mortality in GuillainBarré syndrome. Neurology. 2013;80:1650-4.

24. Yamana $\mathrm{H}$, Moriwaki $\mathrm{M}$, Horiguchi $\mathrm{H}$, et al. Validity of diagnoses, procedures, and laboratory data in Japanese administrative data. J Epidemiol. 2017;27:476-82.

25. Matsuda S, Fujimori K, Fushimi K. Development of casemix based evaluation system in Japan. Asian Pac J Dis Manag. 2010;4:55-66.

26. Walgaard $C$, Lingsma HF, Ruts $L$, et al. Prediction of respiratory insufficiency in Guillain-Barré syndrome. Ann Neurol. 2010;67:781-7.

27. Shariff SZ, Cuerden MS, Jain AK, et al. The secret of immortal time bias in epidemiologic studies. J Am Soc Nephrol. 2008;19:841-3.

28. Mehta $A B$, Cooke $C R$, Wiener $R S$, et al. Hospital variation in early tracheostomy in the United States: a population-based study. Crit Care Med. 2016;44:1506-14.

29. Walgaard C, Lingsma HF, van Doorn PA, et al. Tracheostomy or not: Prediction of prolonged mechanical ventilation in Guillain-Barré syndrome. Neurocrit Care. 2017;26:6-13.

30. Walgaard C, Lingsma HF, Ruts $L$, et al. Early recognition of poor prognosis in Guillain-Barré syndrome. Neurology. 2011;76:968-75.

31. Shigematsu $\mathrm{K}, \mathrm{Nakano} \mathrm{H}$, Watanabe $\mathrm{Y}$. The eye response test alone is sufficient to predict stroke outcome-reintroduction of Japan Coma Scale: a cohort study. BMJ Open. 2013;3:e002736.

32. Quan $\mathrm{H}$, Li B, Couris CM, et al. Updating and validating the Charlson comorbidity index and score for risk adjustment in hospital discharge abstracts using data from 6 countries. Am J Epidemiol. 2011;173:676-82.
33. Saifudheen K, Jose J, Gafoor VA, et al. Guillain-Barré syndrome and SIADH. Neurology. 2011;76:701-4.

34. Sipilä JO, Kauko T, Soilu-Hänninen M. Admission sodium level and prognosis in adult Guillain-Barré syndrome. Int J Neurosci. 2017;127:344-9.

35. Kobori S, Kubo T, Otani M, et al. Coexisting infectious diseases on admission as a risk factor for mechanical ventilation in patients with GuillainBarré syndrome. J Epidemiol. 2017;27:311-6.

36. Green C, Baker T, Subramaniam A. Predictors of respiratory failure in patients with Guillain-Barré syndrome: a systematic review and metaanalysis. Med J Aust. 2018;208:181-8.

37. Redondo-González O, Tenías JM, Arias Á, et al. Validity and reliability of administrative coded data for the identification of hospital-acquired infections: an updated systematic review with meta-analysis and metaregression analysis. Health Serv Res. 2018;53:1919-56.

38. Xu S, Ross C, Raebel MA, et al. Use of stabilized inverse propensity scores as weights to directly estimate relative risk and its confidence intervals. Value Health. 2010;13:273-7.

39. Austin PC. An introduction to propensity score methods for reducing the effects of confounding in observational studies. Multivar Behav Res. 2011:46:399-424.

40. Lawn ND, Wijdicks EF. Post-intubation pulmonary function test in Guillain-Barré syndrome. Muscle Nerve. 2000;23:613-6.

41. Wang $S$, Zhang L, Huang $K$, et al. Predictors of extubation failure in neurocritical patients identified by a systematic review and meta-analysis. PLoS ONE. 2014;9:e112198.

42. Diehl JL, El Atrous S, Touchard D, et al. Changes in the work of breathing induced by tracheotomy in ventilator-dependent patients. Am J Respir Crit Care Med. 1999;159:383-8.

43. Freeman $\mathrm{BD}$, Morris PE. Tracheostomy practice in adults with acute respiratory failure. Crit Care Med. 2012;40:2890-6.

44. Ali MI, Fernández-Pérez ER, Pendem S, et al. Mechanical ventilation in patients with Guillain-Barré syndrome. Respir Care. 2006;51:1403-7.

45. Mehta AB, Syeda SN, Bajpayee L, et al. Trends in tracheostomy for mechanically ventilated patients in the United States, 1993-2012. Am J Respir Crit Care Med. 2015;192:446-54

46. Trouillet $\mathrm{JL}$, Collange O, Belafia F, et al. Tracheotomy in the intensive care unit: guidelines from a French expert panel: The French Intensive Care Society and the French Society of Anaesthesia and Intensive Care Medicine. Anaesth Crit Care Pain Med. 2018;37:281-94.

47. Putensen C, Theuerkauf N, Guenther U, et al. Percutaneous and surgical tracheostomy in critically ill adult patients: a meta-analysis. Crit Care. 2014; 18:544. 